\title{
Infection of the Coffee Berry Borer Hypothenemus hampei (Coleoptera: Scolytidae) by Brazilian Isolates of the Entomopathogenic Fungi Beauveria bassiana and Metarhizium anisopliae (Deuteromycotina: Hyphomycetes)
}

\author{
R. I. SAMUELS, R. C. PEREIRA AND C. A. T. GAVA \\ Laboratory of Plant Protection, Universidade Estadual do Norte \\ Fluminense, Campos dos Goytacazes, RJ 28015-620, Brazil
}

(Received 21 December 2001; accepted 4 April 2002)

The virulence of four fungal isolates (three Beauveria bassiana and one Metarhizium anisopliae) against adult female coffee berry borers ( $C B B$ ) was investigated. The most virulent isolate from initial bioassays, B. bassiana LPP1, with a $L T_{50}$ of 3.4 days, was further investigated by application to berries prior to infestation and to berries already infested with $C B B$. At the highest concentration applied to berries $\left(1 \times 10^{7}\right.$ conidia $\left.\mathrm{mL}^{-1}\right), C B B$ mortality was $83 \%$ (berries inoculated prior to infestation) and $62 \%$ (berries inoculated after infestation).

Keywords: Metarhizium anisopliae, Beauveria bassiana, Hypothenemus hampei, biological control, pathogen specificity, insect, entomopathogenic fungus

The coffee berry borer (CBB), Hypothenemus hampei Ferrari (Coleoptera: Scolytidae), is considered to be one of the most important pest species of cultivated coffee crops, causing reductions in yield and fruit quality (Le Pelley, 1968). It is believed that CBB originated in Africa, but has now spread to all major coffee growing regions of the world (Damon, 2000). Because the insect spends its entire larval stage within the coffee berry, conventional control methods have not been effective in reducing crop losses.

The entomopathogenic fungus Beauveria bassiana is a well-documented natural enemy of H. hampei. It was first recorded infecting this insect in Brazil as early as the 1930's in São Paulo State and more recently in Paraná State (Villacorta, 1984). Natural epizootics have been regularly recorded in Colombia, and have resulted in significantly reduced pest populations (Bustillo \& Posada, 1996). Therefore, B. bassiana has been considered to be one of the most promising biological control agents for this economically important pest species. $B$. bassiana was considered to be an effective component within an integrated pest

Correspondence to: R.I. Samuels, UENF-CCTA-LPP, Av. Alberto Lamego 2000, Campos dos Goytacazes, RJ 28015-620, Brazil. Tel: 55 22-27261681; Fax: 55 22-27261658; E-mail: richard@uenf.br

ISSN 0958-3157 (print)/ISSN 1360-0478 (online)/02/050631-05 $\quad$ (C) 2002 Taylor \& Francis Ltd

DOI: $10.1080 / 0958315021000016298$ 
management program for CBB in Mexico (De La Rosa et al., 2000). However, field tests carried out in Colombia showed that microbial control was not economically viable due to the large quantity of inoculum required to effectively regulate the pest (Baker, 1999). These different conclusions indicate that further work is required to understand the interaction between entomopathogenic fungi and $\mathrm{CBB}$. We compare the virulence of a natural fungal pathogen of $\mathrm{CBB}$ with fungal isolates from other host insects that are considered promising agents for use in biological control of pests in Brazil.

Adult female CBB were obtained from infested coffee berries (Coffee arabica cultivar 'Mundo Novo') collected in Viçosa, Minas Gerais State, Brazil, and maintained in the laboratory under controlled conditions $\left(25 \pm 3^{\circ} \mathrm{C}, 70 \pm 10 \%\right.$ relative humidity $(\mathrm{RH})$ and 14:10 h L:D photoperiod). Insects were maintained on coffee berries which were changed every four months.

Isolates of $B$. bassiana and one isolate of Metarhizium anisopliae were obtained from the collection held at CENARGEN (CG) in Brasilia and from the collection at the Laboratory of Plant Protection (LPP). B. bassiana LPP1 was isolated from an unidentified adult chysomelid (Coleoptera: Chrysomelidae) in Rio de Janeiro State; B. bassiana CG11, from Sternechus subsignatus (Coleoptera: Curculionidae) in Parana State; and B. bassiana LPP5, from $H$. hampei in Minas Gerais State. M. anisopliae CG46 was isolated from Deois incompleta (Homoptera: Cercopidae) in Espírito Santo State.

Fungi were grown on Sabouraud Dextrose Agar at $27^{\circ} \mathrm{C}$ for 15 days before being used in experiments. Conidia were harvested from plates and suspensions were prepared in Tween $80(0.05 \%$ in sterile distilled water). Conidial concentration was determined using a Neubauer haemocytometer and viability was confirmed using standard procedures.

\section{Bioassay 1: Application of fungal isolates to filter paper discs}

$\mathrm{CBB}$ adults were inoculated with fungi by contact with inoculated filter paper discs. Petri dishes (8-cm diameter and 2-cm height) were lined with sterile filter paper discs (Whatman \#1) inoculated with $500 \mu \mathrm{L}$ of a standard suspension containing $1 \times 10^{7}$ conidia $\mathrm{mL}^{-1}$ in $0.05 \%$ Tween 80 . The control discs were treated with $0.05 \%$ Tween 80 only. Five adults were placed in each Petri dish (total of 15 insects per isolate). All isolates were tested at the same time.

Insects were maintained on the treated filter paper discs in a humidity chamber $(>90 \%$ $\left.\mathrm{RH} ; 26^{\circ} \mathrm{C} ; 14: 10 \mathrm{~h} \mathrm{~L}: \mathrm{D}\right)$ for $24 \mathrm{~h}$, after which they were transferred to sterile Petri dishes containing one-quarter of a coffee bean. Dishes were maintained under conditions described above for the duration of the experiment. Insect mortality was monitored daily for 15 days. Dead insects were removed from the Petri dishes and surface sterilized using $95 \%$ ethanol, followed by immersion in sterile distilled water. Insect cadavers were maintained in a humidity chamber ( $>90 \% \mathrm{RH}$ ) to promote fungal outgrowth. Emergence of conidiophores from the cadavers was used to confirm mortality caused by fungal infection. Data collected for time to death were subjected to regression analysis in order to determine $\mathrm{LT}_{50}$ values. The $\mathrm{LT}_{50}$ values for the different isolates were compared using ANOVA followed by Tukey's test for separation of means. All experiments were repeated three times.

\section{Bioassay 2: Direct application of conidial suspensions to non-infested coffee berries}

Coffee berries, in the red berry stage, not perforated by adult CBB, were surface sterilized in order to reduce growth of saprophytes, using a solution of sodium hypochlorite $(0.5 \%)$ for $1 \mathrm{~min}$ and then rinsed in sterile distilled water and allowed to air dry. The berries were then inoculated with $1 \mathrm{~mL}$ of conidial suspension. Only isolate LPP1 was used in this part of the study. Three concentrations were tested: $1 \times 10^{7} ; 1.2 \times 10^{6}$; and $1.0 \times 10^{5}$ conidia $\mathrm{mL}^{-1}$. Conidial suspensions were first applied to the crown of coffee berry and then distributed evenly over the berry using a no. 2 paintbrush. A total of six replicate treatments per concentration were set up, each consisting of five insects and five treated berries. The experiment was repeated three times. The control treatment ( $1 \mathrm{~mL} 0.05 \%$ Tween 80$)$ consisted 
of five berries with five insects for each repetition. Insects and berries were held for $24 \mathrm{~h}$ in a humidity chamber ( $\left.>90 \% \mathrm{RH} ; 25^{\circ} \mathrm{C} ; 14: 10 \mathrm{~h} \mathrm{~L}: \mathrm{D}\right)$ and subsequently maintained as stated in Bioassay 1. Infection by B. bassiana was assessed after 10 days.

\section{Bioassay 3: Direct application of conidial suspensions to pre-infested coffee berries}

Coffee berries in the red berry stage infested with CBB (the posterior part of the abdomen of the insect was exposed) were chosen for application of conidial suspensions of LPP1. The berries were first surface sterilized as described in Bioassay 2, using a fine paint brush, without touching the insects. Treated groups consisted of five infested berries per conidial concentration and the experiment was repeated three times. The berries were individually inoculated with conidial suspensions as described above. Direct inoculation of the insects was avoided. The treated berries were maintained as stated previously. The presence of conidiophores on the cuticle surface of CBB was used to assess insect mortality (infection). Differences between infection rates obtained in Bioassays 2 and 3 were compared using ANOVA followed by Tukey's test.

All of the fungal isolates applied via inoculation of filter paper discs were pathogenic to $H$. hampei, although differences were observed in the virulence of these isolates. Mortality was seen as early as $48 \mathrm{~h}$ after inoculation, with $100 \%$ mortality recorded for treatments with $B$. bassiana isolates LPP1 and LPP5 by day 12 of the experiments. Table 1 shows the values for cumulative per cent mortality 3 and 10 days after inoculation and the LT $_{50}$ values all four isolates. The LT $_{50}$ of LPP1 was lower than that of LPP5, although the values were not significantly different. It is interesting to note that LPP5 was originally isolated from naturally infected CBB and LPP1 was obtained from a chrysomelid beetle, indicating that the host-pathogen interaction may not be specific. Baker (1999) suggested that isolates of B. bassiana are able to move between different host species. In previous studies, 18 isolates caused between 20 and 100\% mortality in CBB and the most virulent isolate (Bb-26) caused $50 \%$ mortality in 4.3 days (De La Rosa et al., 1997). Bb-26 was originally isolated from $\mathrm{CBB}$, and the value for $\mathrm{LT}_{50}$ was similar to that obtained for LPP5. The fact that CBB is susceptible to a range of fungal isolates has important implications for the study of natural epizootics.

Isolate LPP1 was selected as the most virulent isolate for further testing against CBB by inoculation of berries pre-and post-infested coffee berries. Results of Bioassays 2 and 3 are shown in Figure 1. The highest mortalities were obtained for all tested concentrations when fungi were applied to the berries prior to infestation with CBB. However, high levels of mortality were also observed when berries that had already been perforated by $\mathrm{CBB}$ were inoculated. Differences in mortality (infection) levels in berries infested with CBB prior or after inoculation were not statistically significant at each of the concentrations tested. However, there were significant differences in infection when comparing mortality (infection) at the highest and the lowest conidial concentration (Figure 1). It is interesting to note that $\mathrm{CBB}$ were infected by inoculation of berries that had already been perforated, although direct inoculation was avoided. This may be explained by recent studies of CBB behaviour

TABLE 1. Mortality of coffee berry borer caused by infection with four fungal isolates using a concentration of $1 \times 10^{7}$ conidia $\mathrm{mL}^{-1}$

\begin{tabular}{lccc}
\hline Isolate & $\begin{array}{c}\text { Mean \% cumulative } \\
\text { mortality at 3 days } \pm \text { SD }\end{array}$ & $\begin{array}{c}\text { Mean \% cumulative } \\
\text { mortality at 10 days } \pm \text { SD }\end{array}$ & $\begin{array}{c}\text { LT }_{50} \text { (days) } \\
\text { [confidence limits] }\end{array}$ \\
\hline B. bassiana LPP1 & $42.0 \pm 10.2$ & $91.0 \pm 10.4$ & $3.4 \mathrm{a}[3.1-3.8]$ \\
B. bassiana LPP5 & $37.7 \pm 8.1$ & $95.7 \pm 7.5$ & $3.9 \mathrm{a}[3.6-4.3]$ \\
B. bassiana CG11 & $17.6 \pm 4.0$ & $53.0 \pm 20.0$ & $7.0 \mathrm{~b}[6.3-7.8]$ \\
M. anisopliae CG-46 & $4.3 \pm 7.5$ & $46.7 \pm 11.5$ & $9.4 \mathrm{c}[8.5-10.7]$ \\
Control & $2.3 \pm 1.4$ & $14.6 \pm 4.1$ & - \\
\hline
\end{tabular}

Values for $\mathrm{LT}_{50}$ followed by the same letter were not significantly different $(P<0.05)$ using Tukey's test. 


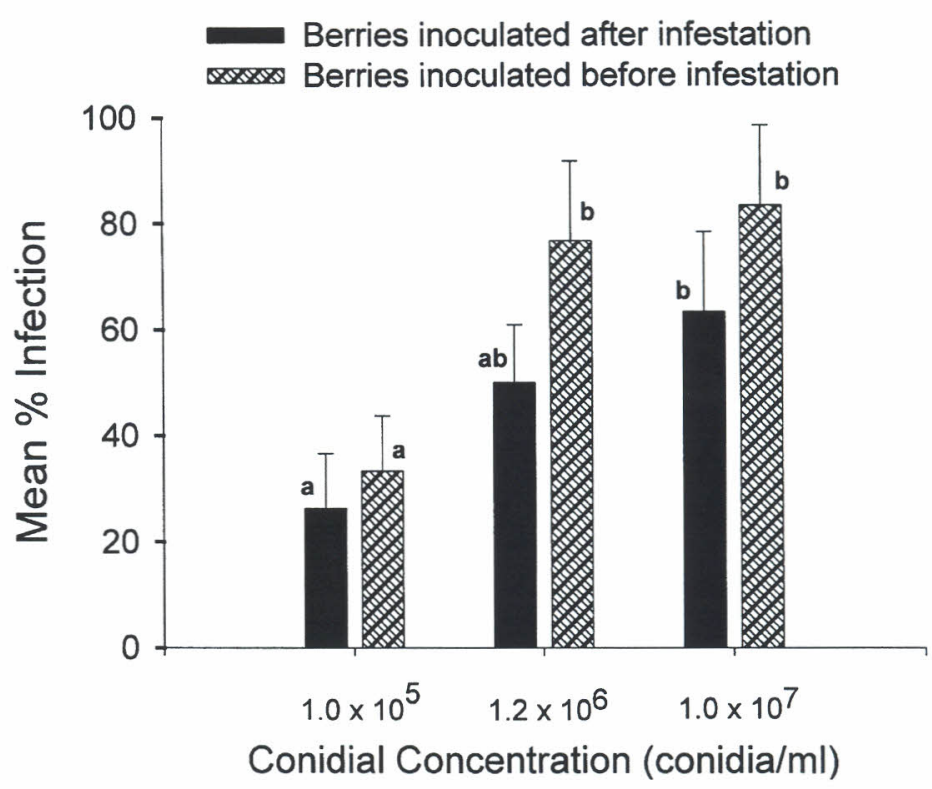

FIGURE 1. Infection of $H$. hampei following inoculation of coffee berries with fungal suspensions before and after $\mathrm{CBB}$ infestation. Infection was determined 10 days after inoculation of berries maintained at $25^{\circ} \mathrm{C}$. Note: The results are expressed as mean percentage infection with error bars representing standard deviation. Bars with the same letter were not significantly different when comparing all treatments, as determined by Tukey's test $(P<0.05)$.

which have shown that during the perforation of the berries, the insect regularly leaves its borehole to deposit excavated material on the berry surface, thus exposing itself to the inoculum (Pereira, unpublished observation).

Few studies have been published on the pathogenicity of entomopathogenic fungi against $\mathrm{CBB}$ in Brazil. Lecuona et al. (1986) investigated mortality caused by direct inoculation of coffee berries with $M$. anisopliae originally isolated from Anthonomus grandis (Coleoptera: Curculionidae). The highest concentration used $\left(1.5 \times 10^{8}\right.$ conidia $\left.\mathrm{mL}^{-1}\right)$ caused $60 \%$ mortality. In the current study, LPP1 caused $83 \%$ mortality when a concentration of $1 \times 10^{7}$ conidia $\mathrm{mL}^{-1}$ was applied indicating that it is a more virulent pathogen. The lower virulence of $M$. anisopliae against $\mathrm{CBB}$, when compared to that of $B$. bassiana, has also been confirmed by Bustillo et al. (1999). The least virulent isolate screened in this study, with an $\mathrm{LT}_{50}$ of 9.4 days, was $M$. anisopliae isolate CG46. Although $M$. anisopliae may prove to be a good biological control agent for CBB in certain situations, it has not been reported as a natural pathogen of CBB.

On the basis of field trails carried out in Colombia, Baker (1999) calculated that it would be necessary to apply $10^{10}$ Beauveria conidia per tree to control CBB infestations, a concentration that is not economically viable. Further studies are required to identify more potent fungal isolates and to better understand the interactions between $\mathrm{CBB}$ and its fungal pathogens, which under certain conditions are capable of naturally controlling CBB populations. Timing of fungal applications will be critical and our results indicate that applications of entomopathogenic fungi to coffee berries before or shortly after CBB infestation may be the most effective. Further tests are currently being carried out in the field to determine population dynamics and timing of infestations using trapping methods. We are also continuing the screening of isolates from various host insects and are comparing the genetic diversity of $B$. bassiana found infecting $\mathrm{CBB}$ in different regions of Brazil. 


\section{ACKNOWLEDGEMENTS}

The authors wish to thank Arli de Fátima de Nogueira da Silva for technical assistance and Dr. Jacquelyn L. Blackmer (USDA) for revising the manuscript. This work was funded by grants from FENORTE, CAPES (094/99) and The British Council (881/13).

\section{REFERENCES}

BAKER, P. (1999) The Coffee Berry Borer in Colombia. Final report of the DFID-Cenicafé-CABI Bioscience IPM for coffee project (CNTR 93/1536A). CABI Bioscience, $154 \mathrm{pp}$.

Bustillo, A.E. \& Posada, F.J. (1996) El uso de entomopatógenos en el control de la broca del café em Columbia. Manejo Integrado de Plagas (Costa Rica) 42, 1-13.

Bustillo, A.E., Bernal, M.G., Benavides, P. \& Chaves, B. (1999) Dynamics of Beauveria bassiana and Metarhizium anisopliae infecting Hypothenemus hampei (Coleoptera; Scolytidae) populations emerging from fallen coffee berries. Florida Entomologist 82, 491-498.

Damon, A. (2000) A review of the biology and control of the coffee berry borer, Hypothenemus hampei (Coleoptera : Scolytidae). Bulletin of Entomological Research 90, 453-465.

De la Rosa, W., Alatorre, R., Trujillo, J. \& Barrera, J.F. (1997) Virulence of Beauveria bassiana (Deuteromycetes) strains against the coffee berry borer (Coleoptera: Scolytidae). Journal of Economic Entomology 90, 1535-1538.

De la Rosa, W., Alatorre, R., Barrera, J.F., \& Toriello, C. (2000) Effect of Beauveria bassiana and Metarhizium anisopliae (Deuteromycetes) upon the coffee berry borer (Coleoptera: Scolytidae) under field conditions. Journal of Economic Entomology 93, 1409-1414.

Le Pelley, R.H. (1968) Pests of Coffee. Longmans, London, $590 \mathrm{pp}$

Lecuona, R.E., Fernández, P.M., Alves, S.B. \& Bleicher, E. (1986) Patogenicidade de Metarhizium anisopliae (Metsch.) Soorok., à Broca-do-Café, Hypothenemus hampei (Ferrari, 1867) (Coleoptera; Scolytidae). Anais da Sociedade de Entomologia Brasil, 15, 21-27.

Villacorta, A. (1984) Ocorrência de Beauveria sp. Infectando a Broca do Café Hypothenemus hampei (Ferrari, 1867) (Coleoptera; Scolytidae) em lavouras no estado do Paraná. Anais da Sociedade de Entomologia Brasil, 13, 177-178. 